\title{
Influence of secondary diagnoses in the development of urinary incontinence after radical prostatectomy
} \author{
Carlos Müller-Arteaga ${ }^{8}$, José Luis Álvarez-Ossorio-Fernández ${ }^{9}$, Filippo Migliorini ${ }^{10}$, \\ Ana Lorenzo-Gómez ${ }^{11}$, María Begoña García-Cenador ${ }^{11}$, Patricia Antúnez-Plaza ${ }^{12}$, \\ Juan Miguel Silva-Abuín ${ }^{13}$, María Fernanda Lorenzo-Gómez ${ }^{2,11}$ \\ ${ }^{1}$ Department of Urology, University Hospital of the Canary Islands, Tenerife, Spain; \\ 2 Department of Urology, University Hospital of Salamanca, Spain; \\ ${ }^{3}$ Department of Urology, Health Complex of Ávila, Spain; \\ ${ }^{4}$ Department of Urology, University Hospital of Pêro da Covilhã, Covilha, Portugal; \\ ${ }^{5}$ Department of Urology, University Hospital of Coimbra (CHUC), Portugal; \\ ${ }^{6}$ Department of Maxillofacial Surgery, Central Hospital Complex of Lisboa, Portugal; \\ ${ }^{7}$ Department of Urology, University Hospital Virgen del Camino of Pamplona, Spain; \\ ${ }^{8}$ Department of Urology, University Hospital Complex of Ourense, Spain; \\ ${ }^{9}$ Department of Urology, University Hospital Puerta del Mar of Cádiz, Spain; \\ ${ }^{10}$ Department of Urology, University Hospital Integrated Trust of Verona, Italy; \\ ${ }^{11}$ Department of Surgery, University of Salamanca, Spain; \\ 12 Department of Pathology, University Hospital of Salamanca, Spain; \\ ${ }^{13}$ Department of Urology, University Hospital San Pedro of Logroño, Spain.
}

Bárbara Padilla-Fernández ${ }^{1}$, Álvaro Julio Virseda-Rodríguez ${ }^{2}$, Lauro Sebastián Valverde-Martínez ${ }^{3}$, Bruno Jorge Pereira ${ }^{4}$, Hugo Coelho ${ }^{5}$, Maria Tatiana Santos-Antunes ${ }^{6}$, Manuel Montesino-Semper ${ }^{7}$,

\begin{abstract}
Summary Objective: To study whether there are factors related to secondary diagnoses $(S D g)$ present in patients with prostate cancer that influence the development of urinary incontinence after radical prostatectomy (RP).

Materials and methods: A retrospective multicenter observational study was performed reviewing the medical records of 430 men who underwent RP due to organ-confined prostate cancer in 9 different hospitals. Two study groups were distinguished: Group A (GA): Patients without urinary incontinence after RP; Group B (GB): patients with any degree of post-surgical urinary incontinence.

Results: Average age at surgery was 63.42 years (range 45-73). 258 patients were continent after surgery and 172 patients complaint of any degree of incontinence after RP. A higher percentage of healthy patients was found in group A (continent after surgery) than in group $B(p=0.001)$.

The most common SDg prior to surgery were hypertension, lower urinary tract symptoms, dyslipidemia, diabetes mellitus and erectile dysfunction, but none did show a greater trend towards post-surgical incontinence.

Conclusions: A better health status prior to surgery is associated to a lower incidence of new-onset urinary incontinence after radical prostatectomy. However, no correlation was found between the most common medical disorders and the development of post-surgical urinary incontinence.
\end{abstract}

KEY WORDS: Radical prostatectomy; Second diagnoses; Urinary incontinence.

Submitted 4 June 2016; Accepted 19 July 2016

\section{INTRODUCTION}

Studies performed in autopsies objectify that up to 30$40 \%$ of men aged 50 or older will show histological evi- dence of tumour cells in the prostate (1), a $9.5 \%$ will have risk of being diagnosed with prostate cancer throughout their life, and 3\% of them will have the probability of dying due to this disease $(2,3)$. Histological signs of prostate cancer have been found in $42 \%$ of patients who died due to other causes $(4,5)$.

Most prostate cancers are organ-confined at diagnosis (6). When the patient's life expectancy is 10 years or greater and his health status is compatible with general anaesthesia, radical prostatectomy achieves the best results in oncological terms (7). Radical prostatectomy is a complex major surgery, which requires dissection and removal of all the prostate gland and disruption and modification of a large part of the anatomical structures that makes up the male sphincteric complex. The different muscles, ligaments and neurovascular elements of the sphincteric complex converge in the prostate apex, in an anatomical funnel, whose upper limit is the prostate gland. The development of urinary incontinence (UI) is one of its most feared complications and is attributed to the technical characteristics of the surgery. The factors that may be associated to an increased risk of developing UI after surgery have been studied, i.e, ageing and deliberate wide resection of the cavernous nerves.

The aim of this study was to evaluate whether there are factors related to secondary diagnoses (SDg) present in patients that influence the development of UI after radical prostatectomy (RP).

\section{MATERIALS AND METHOdS}

A retrospective multicenter observational study was performed. Medical records of 430 men who underwent RP 
due to organ-confined prostate cancer were reviewed. Patients were treated at the University Hospital of Salamanca (Spain), University Hospital Pêro da Covilhã (Covilhã, Portugal), University Hospital and Hospital of Coimbra (Portugal), University Hospital Virgen del Camino (Pamplona, Spain), University Hospital Complex of Ourense (Spain), University Hospital Puerta del Mar (Cádiz, Spain) and University Hospital Integrated Trust Of Verona (Italy). The sample selection was obtained from patients who underwent RP due to organ-confined prostate cancer in the above mentioned health care centres. December 2011 was the date used as reference and cases were selected sequentially in succession and retrospectively. Open and laparoscopic RP were performed routinely at the centres involved in the study, but robot-assisted RP was performed in only one centre and in all cases by the same surgeon.

For our purposes, we collected the information from the patients' medical records of the following variables:

- patient-related variables: Age, BMI, personal history, SDg, ASA score, prostate volume;

- disease-related variables: PSA at diagnosis, Gleason score of the biopsy, percentage of affected cores, presence of HG-PIN or atypical small acinar proliferation (ASAP), cTNM and pTNM, Gleason score of the surgical specimen, affectation of surgical margins;

- surgery-related variables: Centre of intervention, surgi-

cal technique (open, laparoscopic or robot-assisted), intervention's duration, age and experience of surgeon, surgical bleeding, post-surgical complications.

Post-prostatectomy UI was described as any leakage of urine, not present prior to the surgery. Patients without any secondary diagnosis were considered healthy. Patients receiving adjuvant or salvage radiation therapy were excluded from the study.

Two study groups were distinguished: Group A (GA): Patients without urinary incontinence after radical prostatectomy; Group B (GB): patients with any degree of urinary incontinence after radical prostatectomy requiring pads. Patients from GB were stratified according to the UI severity: mild $\leq 100 \mathrm{cc} / 24$ hours; moderate $101-400 \mathrm{cc} / 24$ hours and severe $>401 \mathrm{cc} / 24$ hours according to Pad Test.

The results were analyzed with descriptive statistics, tdistribution, Chi2, Fisher's exact test, ANOVA analysis of variance (with Scheffe's test for normal samples and Kruskal-Wallys for other distributions), Pearson's and Spearman's correlation studies. Statistical significance at $\mathrm{p}<0.05$ was accepted.

The study was approved by the Research Committee of the University Hospital of Salamanca, Spain. All ethical, legal and regulatory requirements for research on human subjects were considered, meeting the ethical principles for medical research of the Declaration of Helsinki.

\section{Table 1.}

General characteristics of the patient and of the tumour in the whole sample and for groups $A$ and $B$.

\begin{tabular}{|c|c|c|c|c|}
\hline & Group A & Group B & $\mathbf{p}$ & Others \\
\hline Age & 62.87 (SD 6.09) & 64.34 (SD 4.57) & 0.26 & Total GA+GB = 63.42 (SD 5.67) \\
\hline BMI & 28.56 (SD 3.59) & 27.96 (SD 5.26) & 0.55 & Total GA+GB = 28.83 (SD 4.32) \\
\hline$\overline{\text { ASA }}$ & 2.01 (SD 0.52) & 2.00 (SD 0.52) & 0.93 & \\
\hline$\overline{\mathrm{PSA}}$ & 8.61 (SD 4.37) & 8.78 ( SD 4.14) & 0.85 & \\
\hline Prostate volume & 41.37 (SD 12.59) & 41.18 (SD18.66) & 0.81 & Measured during prostate biopsy \\
\hline Gleason biopsy & $6.13($ SD 0.61) & 6.52 (SD 0.74) & 0.00 & \\
\hline Tumour burden (\% affected cylinders) & 15.56 (SD 2.02) & 16.40 (SD 2.53) & 0.78 & \\
\hline c TNM & 7.23 (SD 4.02) & 6.75 (SD 3.70) & 0.11 & $*$ \\
\hline P TNM & 3.27 (SD 1.69) & 3.35 (SD 1.56) & 0.74 & ** \\
\hline
\end{tabular}

Table 2.

Most common secondary diagnoses ( $\geq 10 \%)$ in the whole sample.

\begin{tabular}{|c|c|c|c|}
\hline $\begin{array}{l}\text { SDg in the whole sample } \\
(\mathrm{n}=430)\end{array}$ & Type & N & $\%$ \\
\hline HTN & & 182 & 42.32 \\
\hline LUTS & $\begin{array}{c}\text { General } \\
\text { Outlet } \\
\text { Filling } \\
\text { BPH }\end{array}$ & $\begin{array}{c}136 \\
55 \\
16 \\
68 \\
\end{array}$ & $\begin{array}{c}31.62 \\
12.79 \\
3.72 \\
15.81 \\
\end{array}$ \\
\hline Dyslipidemia & $\begin{array}{c}\text { General } \\
\text { Hypercholesterolemia }\end{array}$ & $\begin{array}{c}109 \\
35\end{array}$ & $\begin{array}{c}25.34 \\
8.13 \\
\end{array}$ \\
\hline Diabetes mellitus & $\begin{array}{l}\text { General } \\
\text { NIDDM } \\
\text { IDDM }\end{array}$ & $\begin{array}{c}56 \\
28 \\
6\end{array}$ & $\begin{array}{l}13.02 \\
6.51 \\
1.39\end{array}$ \\
\hline \multicolumn{4}{|c|}{$\begin{array}{l}\text { HTN: arterial hypertension. LUTS: lower urinary tract symptoms. } \\
\text { BPH: benign prostatic hyperplasia. NIDDM: noninsulin-dependent diabetes mellitus. } \\
\text { IDDM insulin-dependent diabetes mellitus. }\end{array}$} \\
\hline
\end{tabular}

\section{Results}

Average age at the moment of the surgery was 63.42 years (SD 5.67, range 45-73). 258 patients were continent after surgery (Group A) and 172 patients complaint of any degree of incontinence after RP (Group B).

Table 1 shows the general characteristics of patients and of the disease in GA and GB.

\section{Surgical technique}

The technique most commonly performed was laparoscopic RP with 217 patients, follow by 190 open RP, and 23 robot-assisted RP (these were all performed at the same centre and by the same surgeon). $56.31 \%$ of patients after open RP were continent, as well as $61.29 \%$ after laparoscopic RP and $91.30 \%$ after robot-assisted RP. 


\section{Secondary diagnoses}

Only $76(17.67 \%)$ out of 430 patients were healthy, without any SDg.

The most common SDg were hypertension (HTN), lower urinary tract symptoms (LUTS), dyslipidemia, diabetes mellitus (DM) and erectile dysfunction (ED). Their distribution in the whole sample and in groups A and B are shown in Tables 2 and 3. A higher percentage of healthy patients was found in group A (continent after surgery) than in group B, difference that was statistically significant. Table 4 shows the distribution of other SDg in the whole sample.

Table 3.

Most common secondary diagnoses in GA and GB.

\begin{tabular}{|l|cc|cc|c|}
\hline Disease & Group A & Group B & P \\
& $\mathbf{n}$ & $\%$ & $\mathbf{n}$ & $\%$ & \\
\hline None: healthy & 61 & 23.64 & 15 & 8.72 & 0.001 \\
\hline HTN & 96 & 37.20 & 66 & 38.37 & 0.8393 \\
\hline DM & 35 & 13.56 & 5 & 2.90 & 0.0001 \\
\hline ED previous to prostatectomy & 13 & 5.04 & 10 & 5.81 & 0.8275 \\
\hline Dyslipidemia & 56 & 21.70 & 44 & 25.58 & 0.3541 \\
\hline
\end{tabular}

\section{Table 4.}

Other SDg in the whole sample.

\begin{tabular}{|c|c|c|c|}
\hline $\begin{array}{l}\text { Other SDg } \\
\text { in the whole sample } \\
(n=430)\end{array}$ & Type & $\mathbf{N}$ & $\%$ \\
\hline Urological & $\begin{array}{l}\text { Relative with prostate cancer } \\
\text { Bladder cancer } \\
\text { Erectile dysfunction } \\
\text { Hydrocele } \\
\text { Phimosis }\end{array}$ & $\begin{array}{c}6 \\
4 \\
27 \\
4 \\
6\end{array}$ & $\begin{array}{l}1.39 \\
0.93 \\
6.27 \\
0.93 \\
1.39\end{array}$ \\
\hline Neurological & $\begin{array}{l}\text { Cerebrovascular accident } \\
\text { Sequels of meningitis or cerebral palsy } \\
\text { Pituitary adenoma }\end{array}$ & $\begin{array}{l}7 \\
5 \\
3\end{array}$ & $\begin{array}{l}1.62 \\
1.16 \\
0.69\end{array}$ \\
\hline Osteoarticular & $\begin{array}{l}\text { Herniated disc } \\
\text { Ankylosing spondylitis } \\
\text { Hip prosthesis }\end{array}$ & $\begin{array}{c}26 \\
3 \\
6\end{array}$ & $\begin{array}{l}6.04 \\
0.69 \\
1.39\end{array}$ \\
\hline Respiratory & $\begin{array}{l}\text { Asthma } \\
\text { COPD } \\
\text { OSAS }\end{array}$ & $\begin{array}{c}12 \\
7 \\
14\end{array}$ & $\begin{array}{l}2.79 \\
1.62 \\
3.25\end{array}$ \\
\hline Cardiac & $\begin{array}{l}\text { Coronary artery disease } \\
\text { Valvular heart disease } \\
\text { Arrhythmia: AF }\end{array}$ & $\begin{array}{c}12 \\
11 \\
8\end{array}$ & $\begin{array}{l}2.79 \\
2.56 \\
1.86\end{array}$ \\
\hline Hepatopathology & $\begin{array}{l}\text { Steatosis } \\
\text { Idiopathic } \\
\text { Chronic with portal hypertension }\end{array}$ & $\begin{array}{c}11 \\
8 \\
5\end{array}$ & $\begin{array}{l}2.56 \\
1.86 \\
1.16\end{array}$ \\
\hline Gastrointestinal & $\begin{array}{l}\text { Esophagitis } \\
\text { Gastritis } \\
\text { Peptic ulcer } \\
\text { Hiatal hernia } \\
\text { Irritable bowel } \\
\text { Colon polyps } \\
\text { Haemorrhoids }\end{array}$ & $\begin{array}{c}6 \\
15 \\
7 \\
8 \\
4 \\
6 \\
8\end{array}$ & $\begin{array}{l}1.39 \\
3.48 \\
1.62 \\
1.86 \\
0.93 \\
1.39 \\
1.86\end{array}$ \\
\hline \multicolumn{2}{|l|}{ Obesity (BMI > 30) } & 21 & 4.88 \\
\hline \multicolumn{2}{|l|}{ Hyperuricemia } & 28 & 6.51 \\
\hline \multicolumn{2}{|c|}{ Chronic renal failure under dialysis } & 6 & 1.39 \\
\hline \multicolumn{2}{|l|}{ Depression } & 29 & 6.74 \\
\hline Sense organs & $\begin{array}{l}\text { Glaucoma } \\
\text { Hearing loss } \\
\text { Vertigo }\end{array}$ & $\begin{array}{c}11 \\
14 \\
3\end{array}$ & $\begin{array}{l}2.56 \\
3.25 \\
0.69\end{array}$ \\
\hline
\end{tabular}

\section{Discussion}

LUTS infections, functional and cognitive impairment, neurological disorders and prostatectomy (8) are considered risk factors for UI in older men.

In men in the study, considering the age and without prostatectomy, less than $1 \%$ would have some degree of urinary incontinence. A prevalence of up to $40.77 \%$ was observed in the 6 weeks following the surgery.

Incontinence is described as any leakage of urine that was not present prior to the surgery. $33.33 \%$ had severe urinary incontinence, $27.45 \%$ moderate incontinence and $39.22 \%$ mild incontinence.

This prevalence is higher than that reported in the literature: $0-11 \%$ for minimally invasive prostatectomy and $3-20 \%$ for open surgery (9). This discordance may be due to the used UI definition: any leakage of urine, no matter how scarce or transitory it is, which was not present before. Data were recorded in the first consultation after surgery. A trend to improvement of the results of continence was observed during all the follow-up time, until 48.12 months. At 24 months, only $26.7 \%$ of patients suffered from some degree of incontinence. These results were closer than those reported by other authors.

\section{Second diagnoses and urinary incontinence after radical prostatectomy}

The prevalence of SDg in the sample does not differ from that observed in the general population. The most common are HTN, LUTS, dyslipidemia and DM (42.32\%, $31.62 \%, 25.34 \%$ and $13.02 \%$ respectively).

LUTS and DM have been associated to the risk for UI in men, related to radical prostatectomy but also without prostatectomy history $(10,11)$.

DM has been proposed as an independent factor for the development of urinary incontinence. It is usually associated to age over 65 and to the use of insulin as markers of severity $(11,12)$. In our series is noteworthy that the prevalence of DM in the group of incontinent patients $(2.90 \%)$ is lower than in the group of continents $(13.56 \%)$ ( $p<0.0001)$. DM type 2 or noninsulindependent DM was the most common in the sample, and it had a shorter evolution time than DM type 1. These data are important since both the evolution time and the intrinsic insulin deficiency have been proposed as determinants of axonal damage that eventually causes loss of urine in elderly patients $(13,14)$.

$14.22 \%$ of patients were diabetic, from which $77.89 \%$ had DM type 2 with a similar pattern of distribution in the groups A and B $(78.21 \%$ in group A and $76.35 \%$ in group B).

LUTS prior to the RP has also been reported as a risk factor for developing urinary incontinence $(8,15)$. Neuroanatomical abnormalities in structures related to male sphincter complex would lead to a series of modifications that would predispose to suffer UI after prostatectomy. These abnormalities could be caused either by a trabeculated bladder, used to withstand high filling pressures (with consequent fibromuscular, irreversible damage) in relation to a distal obstructive element (usually BPH) or by a primary hypo- or hypertonic bladder (much less common). 
In our series, $31.62 \%$ of patients had some degree of LUTS with an average IPSS of 8.23 points (mild). It was measured in the consultation, by protocol and prior to the surgery, as well as the flowmetry. The flowmetry was performed in $88.34 \%$ of the patients included in the study and in $92.98 \%$ of patients classified as suffering from LUTS; it showed an average of $9.33 \mathrm{ml} / \mathrm{min}$ (obstructive). Epidemiological data (men over 60 years), the rate of prostate symptoms and urinary flow results suggest a tendency to suffer obstructive LUTS.

The results after surgery vary in this subgroup of patients. Patients with any degree of UI after RP are similar regarding affectation by LUTS in the groups of mild, moderate and severe incontinence $(35.29 \%, 32.60 \%$ and $33.04 \%$ respectively) $(\mathrm{p}=0.88)$. Therefore, suffering from LUTS prior to RP would not be related to the presence of IU after RP. A sphincter complex used to filling and emptying pressures higher than normal could be more prepared than a normal sphincter complex to the aggression of the RP, as the first has a tendency to hyperpressure and hypertrophy.

Broader studies would be necessary to investigate these pathophysiological aspects.

Regarding the presence of affected margins in the surgical piece, only the results from one centre (level 4 public hospital) could be studied. It contributed to the sample with 153 cases. Affected margin was defined as the surgical piece in which tumour cells are less than $2 \mathrm{~mm}$ from the stain with Indian ink of the edge (16). No difference between GA (24.04\%) and GB (25.71\%) ( $\mathrm{p}=$ 0.4344 ) was observed in this centre regarding the affectation of margins, as it has been previously reported by this research group (17).

The absence of SDg or patients with better health condition was associated with not suffering any degree of UI after RP $(23.64 \%$ in GA versus $8.72 \%$ in GB, p < 0.001$)$. This finding is consistent with other published results $(9,12)$

Erectile dysfunction prior to the surgery has been proposed as a risk factor for IU after RP (18). The hypothesis that erectile dysfunction is associated to sensorineural deficits or to a worse overall condition of sphincter complex structures could explain this relationship with UI (19).

In our series, there was no difference in the distribution of hypertension and erectile dysfunction between GA and GB (Table 4).

\section{Conclusions}

Age, body mass index, having diabetes mellitus, hypertension or symptoms of lower urinary tract prior to the surgery do not influence the development of urinary incontinence after radical prostatectomy.

However, a better health condition expressed as absence of disease is associated to a lower incidence of new-onset urinary incontinence after radical prostatectomy.

\section{AUthOR'S CONTRIBUTIONS}

Álvarez-Ossorio-Fernández (Patient selection, data extraction); Antúnez-Plaza (Statistical analysis); Coehlo (Patient selection, data extraction); García-Cenador (Study design, manuscript review); Lorenzo-Gómez, A (Data extraction); Lorenzo-Gómez, MF (Study design, patient selection, manuscript review); Migliorini (Patient selection, data extraction); Montesino-Semper (Patient selection, data extraction); Müller-Arteaga (Patient selection, data extraction); PadillaFernández (Study design, manuscript writing); Pereira (Patient selection, data extraction); Santos-Antunes (Data extraction); Silva-Abuin (Patient selection, data extraction); Valverde-Martínez (Data extraction, statistical analysis); Virseda-Rodríguez (Statistical analysis, manuscript writing).

\section{References}

1. Parkin D, Pisani P, Ferlay J. Estimates of worldwide incidence of eighteen mayor cancers in 1985. Int J Cancer. 1993; 54:594-606.

2. Ilic D, O'Connor D, Green S, Wilt T. Screening for prostate cancer: a Cochrane systematic review. Cancer Causes Control. 2007; 18:279-85.

3. Bartsch G, Horninger W, Klocker H, et al. Tyrol Prostate Cancer Screening Group. Prostate cancer mortality after introduction of prostate specific antigen mass screening in the Federal State of Tyrol, Austria. Urology. 2001; 58:417-24.

4. Jemal A, Siegel R, Ward E, et al. Cancer statistics, 2008. CA Cancer J Clin. 2008; 58:71-96.

5. Jensen OM, Estève J, Moller H, Renard H. Cancer in the European Community and its members states. Eur J Cancer. 1990; 26:1167-256.

6. Altwein S. Screening of prostatic carcinoma: a critical analysis. The problem of screening and early diagnosis. Munich, 19-21 March 1992. Clin Investig. 1992; 70 (9 Suppl):1-8.

7. Heidenreich A, Bellmunt J, Bolla $M$, et al. EAU guidelines on prostate cancer. Part I: screening, diagnosis, and treatment of clinically localised disease. Actas Urol Esp. 2011; 35:501-14.

8. Lucas MG, Bedretdinova D, Bosch JLHR, et al. Guidelines on Urinary Incontinence. Urology EAo, editor. Arhein, Netherland: Uroweb; 2014; p.126

9. Ficarra $V$, Novara $G$, Rosen RC, et al. Systematic review and meta-analysis of studies reporting urinary continence recovery after robot-assisted radical prostatectomy. Eur Urol. 2012; 62:405-17.

10. Lucas M, Bosch J, Cruz F, et al. Guidelines on Urinary Incontinence. In: Urology EAo, editor. European Association of Urology Guidelines: European Association of Urology. 2012; p. 7.

11. Offermans MP, Du Moulin MF, Hamers JP, et al. Prevalence of urinary incontinence and associated risk factors in nursing home residents: a systematic review. Neurourol Urodyn. 2009; 28:288-94.

12. Hsu A, Conell-Price J, Stijacic-Cenzer I, et al. Predictors of urinary incontinence in community-dwelling frail older adults with diabetes mellitus in a cross-sectional study. BMC Geriatr. 2014; $14: 137$.

13. Wiedemann A, Anding R, Kirschner-Hermanns R. (Characteristics of urinary incontinence in the elderly). Der Urologe Ausg A. 2014; 53:1543-50.

14. Marini G, Rinaldi JdC, Damasceno DC, et al. Changes in the extracellular matrix due to diabetes and their impact on urinary continence. Rev Bras Ginecol Obstet. 2014; 36:328-33.

15. Irwin D, Milsom I, Hunskaar S, et al. Population-based survey 
of urinary incontinence, overactive bladder, and other lower urinary tract symptoms in five countries: results of the EPIC study. Eur Urol. 2006; 50:1306-14.

16. Tan PH, Cheng L, Srigley JR, et al. International Society of Urological Pathology (ISUP) Consensus Conference on Handling and Staging of Radical Prostatectomy Specimens. Working group 5: surgical margins. Mod Pathol. 2011; 24:48-57.

17. Virseda-Rodríguez AJ, Valverde-Martínez LS, Pereira BJ, et al.
Urinary incontinence after radical prostatectomy. In: Urología AEd, editor. 79 Annual Meeting of the Spanish Urological Association; Tenerife (Spain): Asociación Española de Urología; 2014.

18.Carlsson S, Drevin L, Loeb S, et al. Population-based study of long-term functional outcomes after prostate cancer treatment. BJU Int. 2016; 117:E36-45

19. Glickman L, Godoy G, Lepor H. Changes in continence and erectile function between 2 and 4 years after radical prostatectomy. J Urol. 2009; 181:731-5.

\section{Correspondence}

Barbara Padilla-Fernández, MD (Corresponding Author) padillaf83@hotmail.com

Department of Urology, University Hospital of the Canary Islands Carretera de Ofra, s/n. 38320 - San Cristóbal de La Laguna, Tenerife, Spain

Alvaro Julio Virseda-Rodríguez, MD

Department of Urology, University Hospital of Salamanca Salamanca, Spain

Lauro Sebastian Valverde-Martinez, MD

Department of Urology, Health Complex of Ávila, Avila, Spain

Bruno Jorge Pereira, MD

Department of Urology, University Hospital of Pêro da Covilhã Covilha, Portugal

Hugo Coelho, MD

Department of Urology, University Hospital of Coimbra (CHUC) Coimbra, Portugal

Maria Tatiana Santos-Antunes, MD

Department of Maxillofacial Surgery, Central Hospital Complex of Lisboa Lisboa, Portugal

Manuel Montesino-Semper, MD

Department of Urology, University Hospital Virgen del Camino of Pamplona, Pamplona, Spain

Carlos Müller-Arteaga, MD

Department of Urology, University Hospital Complex of Ourense Ourense, Spain

Jose Luis Álvarez-Ossorio-Fernández, MD

Department of Urology, University Hospital Puerta del Mar of Cádiz Cadiz, Spain

Filippo Migliorini, MD

Department of Urology, University Hospital Integrated Trust Of Verona Verona, Italy

Ana Lorenzo-Gómez, MD

Department of Surgery, University of Salamanca, Salamanca, Spain

Maria Begona García-Cenador, MD

Department of Surgery, University of Salamanca, Salamanca, Spain

Patricia Antúnez-Plaza, MD

Department of Pathology, University Hospital of Salamanca

Salamance, Spain

Juan Miguel Silva-Abuin, MD

Department of Urology, University Hospital San Pedro of Logroño, Spain

Maria Fernanda Lorenzo-Gómez, MD

Department of Urology and Surgery, University Hospital of Salamanca Salamanca, Spain 